\title{
EL LENGUAJE DE LOS SUEÑOS EN LA ÚLTIMA NIEBLA: LA METÁFORA DEL EROS
}

\author{
POR \\ Adriana Méndez Rodenas \\ University of Iowa
}

Con la frase "todo lo que pasa en esa novela pasa dentro de la cabeza y del corazón de una mujer que sueña y ensueña", Amado Alonso describe el nudo central de La última niebla (1934) (11; citado en Agosín 26, 28-29). Una protagonista sin nombre va sumergiéndose en una dimensión imaginaria con el invento de un sueño de amor que llega a sustituir la oprimente realidad de una vida matrimonial sin deseo ni pasión. Alonso es el primero en aclamar la "aparición de una novelista", María Luisa Bombal, quien con La última niebla escribe fiel a la poética moderna una prosa transformada en sugestiva poesía (14).

Desde la tesis temprana de Hernán Vidal de que Bombal expone la "feminidad enajenada" hasta la propuesta de Marjorie Agosín de que la protagonista de La última niebla se convierte en heroína romántica (28), todos los críticos de la novela han intentado resolver el misterioso poder evocativo de la obra. ¿Cómo logra Bombal crear la impresión de que el sueño de amor ocurre en un plano subjetivo, mientras que la amenazante niebla cubre por entero la realidad exterior $u$ objetiva? Frente a estas tensiones evidentes en la obra de Bombal, los críticos han coincidido en que el problema planteado en la narrativa de Bombal es la disolución de las fronteras entre la realidad y la fantasía, el ensueño y la cotidianidad (Vidal 79-80, 88; Agosín 28; Guerra-Cunningham 69 y Goiç 146-147). Otro acercamiento que evita caer en una dicotomía estricta entre realidad objetiva y fantasía es la de Lynnette Seator cuando sugiere que "[e]sta vacilación entre la ilusión y la realidad ... está vista sólo por el punto de vista de la soñadora" (39). Mediante el subjetivismo lírico, Bombal adentra al lector en el mundo interior de su protagonista, dándonos así un mapa psíquico de la desdichada mujer. ${ }^{1}$

\footnotetext{
' Podría extenderse esta línea de pensamiento y sugerir que Bombal muestra en todas sus ficciones el "universal femenino" (La historia de María Griselda) o el arquetipo de un (posible) sujeto femenino ("Las islas nuevas"). En este sentido, la autora declara: "no creo que los derechos sociales reconocidos oficialmente en la actualidad a la mujer puedan hacer cambiar lo íntimo de su naturaleza. Creo que somos y seguiremos siendo la eterna mujer. La idealista, sensible, sacrificada, ávida ante todo de dar y recibir amor" (Marjorie Agosín, "Entrevista con María Luisa Bombal", 6). A pesar de la polémica en torno a esta idea, habría que cuestionar la validez de estudiar la obra de Bombal desde
} 
Es así que la niebla llega a convertirse en una "metáfora total"; por un lado, es el principio organizador de la novela y por otro, la cifra elusiva de la ambivalencia entre lo real y lo fantástico característico de las ficciones de Bombal (Goiç 156; Guerra-Cunningham 73). Pero con la excepción de los primeros comentarios de Amado Alonso, poco se ha dicho relativo a la forma en que metáfora y lenguaje poético sostienen la impresión de que en La última niebla no estamos frente al mundo "real" sino mirando "la ventana abierta" del inconsciente, sumergidos durante el tiempo de lectura en el mundo "irreal" de la imaginación y del deseo. Alonso acierta al señalar que "la función poética constante de la niebla es la de ser el elemento formal del ensueño en que vive zambullida la protagonista" (23). Y otra vez Seator apunta la zona intermedia entre vida consciente e inconsciente en que acontece la obra, "el estado flotante entre sueño y realidad" (41).

El misterioso contacto entre poesía y ensoñación que ha cautivado a todo lector de $L a$ última niebla tiene que ver con la representación de lo Imaginario, entendido tanto en su acepción lacaniana de enlace entre el yo y el Otro como en su sentido más convencional de impulso imaginativo. ${ }^{2}$ En La última niebla, la escena donde la protagonista se encuentra con el amante se ha interpretado como escape imaginario a una vida emocionalmente estéril. Dice, por ejemplo, Guerra-Cunningham: "abrumada por el peso de la rutina y el inexorable transcurso de una existencia vacía, la heroína encuentra su razón de ser en una relación amorosa cuya veracidad objetiva no se resuelve en la novela" (51). En nuestra lectura, proponemos, sin embargo, que la imaginación de la protagonista vuela hacia un amante ideal como compensación psíquica a la represión de su deseo por un marido indiferente y tiránico, que le niega a la esposa toda expresión de individualidad.

Es más, si leemos La última niebla en base al descubrimiento freudiano de que el sueño significa siempre el cumplimiento de un deseo no satisfecho, notamos que el ensueño de la protagonista funciona a la manera de un wish-fulfillment, ya que es sólo mediante el sueño que la protagonista puede realizar su deseo (véase el ya clásico estudio de Freud, The Interpretation of Dreams, 154). Veremos que los mecanismos que según Freud engendran el sueño - la condensación y el desplazamiento - son los mismos que motivan el ensueño de la protagonista bombaliana (Freud 209, 215, 315, 343). Proponemos, entonces, que "la creación del ensueño en La última niebla" remite, en definitiva, al lenguaje poético, y que éste funciona en la obra de manera análoga al lenguaje de los sueños. Es Lacan quien ha mostrado la correspondencia entre los mecanismos del sueño y la poesía.

una perspectiva estrictamente sociológica o inclusive desde un feminismo que aboga únicamente por los derechos de la mujer sin considerar su universo afectivo. En efecto, las ficciones de Bombal nos muestran que el patriarcado le concede a la mujer el mismo estatuto simbólico, no obstante las diferencias de clase o de origen social entre ellas.

${ }^{2}$ En Lacan, lo imaginario remite al "estadio del espejo" en que el niño descubre su cuerpo por vez primera. Esta etapa marca la diferenciación del yo del cuerpo materno y la resolución del edipo, concomitante a la entrada en el reino de lo simbólico. Sugerimos en esta lectura una correspondencia entre lenguaje poético y procedimiento psicológico. Según Lacan, el imaginario se apoya en una figura poética: "[p]ara localizar [al imaginario] en el estadio del espejo, sepamos ... leer en él el paradigma de la definición propiamente imaginaria que se da de la metonimia: la parte por el todo". "De nuestros antecedentes", Escritos 1, 8. 
Como para Lacan el inconsciente es un efecto de lenguaje, o una función del significante, la condensación correspondería a la metáfora y el desplazamiento, a la metonimia ("La instancia de la letra en el inconsciente o la razón desde Freud", 196, 200-203). Quisiera mostrar aquí cómo en La última niebla ambos mecanismos, transferidos al lenguaje poético, indican el complicado proceso psíquico que resulta de la represión del deseo erótico femenino, la anulación del instinto vital de la mujer - anónima por representar a todas las mujeres - en el sistema patriarcal.

Si en la vida consciente la protagonista de La última niebla se ve obligada a reprimir su deseo para satisfacer la convención social del matrimonio (Guerra-Cunningham 3739), este impulso pasional es forzado a recluirse, por necesidad, en el inconsciente. En La interpretación de los sueños, Freud ha mostrado cómo el material reprimido en el inconsciente aflora a la consciencia durante el sueño (589-592). En otras palabras, a través del sueño el deseo reprimido rompe la censura impuesta por la conciencia y empieza a "hablar" en el lenguaje imaginario del paisaje onírico. Por supuesto que la misma función compensatoria se le otorga también al sueño diurno, a la fantasía, ensoñación o daydreaming. En la novela de Bombal, el inframundo inconsciente de la protagonista se despliega a modo de metáfora en su imaginación o capacidad ensoñadora. Ella vive suspendida en el reino de lo imaginario constituido por su deseo, "flotando entre la inconsciencia que es su vida y la pasión suprema que encuentra en el sueño" y que le es negada en la vida real (Seator 39). De ahí que ella transite entre lo real y lo irreal, entre la realidad y la fantasía, mediante la ensoñación o el daydreaming.

Interpretamos el relato de Bombal desde el punto de mira psicoanalítico que establece, no una ruptura entre realidad y fantasía, sino, al contrario, una continuidad entre lo vivido psíquicamente en ambos planos. En otros términos, el sumergido universo de la psique invierte lo real y lo imaginado conforme a las necesidades de su propia supervivencia, y no de acuerdo a la lógica racional. Freud declara que los "[s]ucesos reales e imaginarios ... aparecen en los sueños con igual validez", lo cual ocurre también en el caso de "la producción de estructuras psíquicas de mayor importancia" como el trauma sexual infantil (323 y nota 1). Lacan también ha apuntado el mismo fenómeno de la continuidad o inversión recíproca entre mundo consciente e inconsciente cuando afirma que "la eficacia del inconsciente no se detiene al despertar" (199).

Resistiendo la opinión crítica mayoritaria de asombro ante la ambigüedad característica de Bombal, creemos que "la eliminación de límites exactos y racionales entre la vivencia onírica, la ensoñación y la realidad objetiva" (Guerra-Cunningham 70) es el acierto poético con que Bombal logra trazar el intercambio de fuerzas al interior de la vida psíquica. Mi lectura insiste en que el "aura" imaginativa de La última niebla corresponde a la poetización del deseo (reprimido) femenino. No es fortuito notar aquí la resonancia entre Aura (1962) de Carlos Fuentes y la obra de Bombal, puesto que ambas utilizan el mismo procedimiento: tender el velo de lo fantástico mediante el lenguaje narrativo. Si en el relato de Fuentes prevalecen la narración en segunda persona y la desintegración del tiempo, en Bombal se combinan la metáfora recurrente de la niebla, las escenas y los personajes paralelos, y la curiosa yuxtaposición entre lo interior y lo exterior. Tales procedimientos parecen cumplir la idea de Freud de que lo fantástico es meramente la inversión de lo familiar, y especialmente 
de un elemento que ha sufrido represión y por tanto emerge de nuevo bajo el velo de lo suprarreal. ${ }^{3}$

El relato de Bombal está teñido de niebla porque esta imagen borra metafóricamente los límites imprecisos entre vida consciente e inconsciente, que es la zona donde acontece la narración. Es significativo notar que la niebla aparece no sólo afuera, sino además adentro de la psique de la protagonista en un sueño:

La niebla se estrecha, cada día más, contra la casa. Ya hizo desaparecer las araucarias cuyas ramas golpeaban la balaustrada de la terraza. Anoche soné que, por entre las rendijas de las puertas y ventanas, se infiltraba lentamente en la casa, en mi cuarto, y esfumaba el color de las paredes, los contornos de los muebles, y se entrelazaba a mis cabellos, y se me adhería al cuerpo y lo deshacía todo, todo (16; citado en GuerraCunningham 56)

Esta pesadilla simboliza no sólo la represión del deseo que vive la protagonista bajo la mirada vigilante del marido, sino que anticipa con todo propósito la ensoñación del amante. De hecho, todo el ambiente de esa famosa escena está imbuido y condicionado por la lógica onírica. Desde las primeras páginas, en que nota la indiferencia de Daniel, la protagonista se ve invadida por el sueño (Bombal 11), mientras siente "una turbia inquietud" y anhela descifrar el mensaje que le envía el inconsciente: "Noche a noche he tratado, también en vano, de volver a encontrar el mismo sueño" (Bombal 12; citado en Seator 40). Es como si el deseo reprimido empezara "a tomar forma, a brotar de la subconsciencia" de la narradora (Seator 40), hasta el punto en que se invierten, con la precisión característica de la psique, el ámbito real con el imaginario. Lo explica así Seator:

El mundo de los sueños empieza a desarrollarse con el baño del estanque, preludio a la soñada consumación del amor, que despierta todos los sentidos de ella a una voluptuosidad superreal. Tiene la cualidad del sueño dentro del ambiente actual de la naturaleza. En cambio, la escena amorosa también brillante, sensual [,] tiene mayor realismo por ser alejada del ambiente actual. La impresión de ésta es de un episodio vivido, la otra, un estado mental extraordinario (41).

Si traemos a mente la idea de Freud de que la psique "confunde" oportunamente lo real y lo soñado, esto explica por qué un sueño prepara la inserción de la protagonista en su mundo de ensueño. Antes de salir a caminar por la ciudad, ella duerme inquieta al lado de Daniel, "sin llegar a conciliar el sueño" (Bombal 17). La escena de amor surge, entonces, gracias a uno de los procedimientos psíquicos que producen el sueño: el desplazamiento o intercambio de energías. Según Freud, el desplazamiento es una operación psíquica en la cual los elementos más significativos del insconsciente descargan su contenido afectivo en otros. La fuerza emotiva así desplazada se localiza en elementos a primera vista triviales

3 "It may be true that the uncanny [unheimlich] is something which is secretly familiar [heimlich], which has undergone repression and then returned from it, and that everything that is uncanny fulfills this condition." Freud, "The Uncanny", SE, XVII, 245. Citado en Berg, nota 11, 27. 
o insignificantes, pero que sustituyen simbólicamente a los primeros, al adquirir o asumir el significado emotivo de los objetos de amor originales (343; 209-210).

Si con este conocimiento regresamos a la escena del ensueño, notamos que la protagonista crea su sueño de amor porque cobra conciencia de que nunca será amada ni deseada por su esposo, y por temor a que su cuerpo "se marchite" en esos largos años vacíos de pasión (18). Ella se ha casado con un hombre no amado, sólo por evitar la condena de ser "una solterona arrugada" en la sociedad patriarcal (10). Esto resulta en que toda la vida psíquica de ella va a depender del hilo tenue de la primitiva función de desplazar un contenido afectivo por otro. A un nivel muy profundo de su economía libidinal, la protagonista ha hecho un ajuste de fuerzas, teniendo que intercambiar la vida con la muerte al ver negado su natural erotismo: "[e]s muy posible desear morir porque se ama demasiado la vida" (18). Como Ana María, La amortajada (1938), la protagonista de La última niebla demuestra la verdad psíquica de que la muerte del deseo conduce a un deseo de muerte, esto porque los polos instintivos de Eros y Thanatos están unidos en el continuum biológico-psíquico (Freud, Beyond the Pleasure Principle, 32, 48). Entonces para preservar su instinto vital y su deseo, para sobrevivir de algún modo en una situación psicológicamente dañina, la protagonista desplaza su frustrada energía en un hombre-misterio que se le aparece "[e]ntre la oscuridad y la niebla" (18), o sea, entre las sombras de su propio inconsciente. ${ }^{4}$

Si bien el ensueño en sí emana del desplazamiento, la imagen del amante cobra intensidad mediante el mecanismo de la condensación. Freud explica este mecanismo en términos de una identificación que la psique efectúa entre una persona y otra; la primera es alguien que nos causa rechazo y la segunda, quien comparte algunos de los rasgos negativos de aquélla. Como el personaje indeseado se censura en el inconsciente, durante el sueño se evade esta prohibición y el inconsciente permite poner en contacto a estas dos personas, creando una "figura compuesta" que vendría a reunir las características de ambas (Freud, The Interpretation of Dreams, 355-356). En La última niebla el profundo resentimiento que la protagonista siente hacia su marido no puede tener entrada en su vida consciente, por la precisa razón de que él es legal y socialmente su cónyuge. Admitir la verdad de su vida y reconocer de que no hay otra alternativa le crea un conflicto que el mecanismo de

\footnotetext{
${ }^{4}$ Hernán Vidal considera que la protagonista inventa su sueño a partir de "un amante antes soñado y olvidado al despertar, que reencontrará finalmente en la alucinación de una noche de niebla" (90). En términos freudianos, Vidal propone que un sueño olvidado le ha servido a ella de dream-thought o motivo generador del ensueño. Esta tesis es insostenible si uno se remite, en primer lugar, a la teoría psicoanalítica, que postula las fuentes de los sueños en las impresiones o sucesos vividos el día anterior: "Dominan nuestros pensamientos (dream-thoughts) el mismo material que nos ha ocupado durante el día y sólo nos molestamos en sonfar con las cosas que nos han dado motivo de reflexion durante el día" (Freud, The Interpretation of Dreams, 207). Por supuesto que Freud admite que estas impresiones recientes remontan, a su vez, a la memoria de algún suceso emotivamente impactante del pasado o de la infancia (212-213). En segundo lugar, el texto de Bombal sugiere que el dream-thought más inmediato es el recuerdo del amante de Regina, descrito en términos muy parecidos al futuro seductor imaginario: "Lleva la camisa entreabierta y de su pecho se desprende un olor a avellanas y a sudor de hombre limpio y fuerte" (16).
} 
resistencia de la psique intenta resolver. ${ }^{5}$ La única salida que escapa a la censura es la identificación inconsciente entre el marido rechazado y el amante deseado. Este último es una figura compuesta no sólo de las cualidades de un amante ideal, sino también de lo que le falta al marido. Ambos hombres están pactados por un elemento en común - la capacidad de entrega erótica, ausente en el marido pero muy presente en el amante. Esta conexión inconsciente se representa al final de la escena del ensueño mediante una rápida yuxtaposición entre las dos figuras: "Y es como si él anduviera aún a mi lado ... para siempre" - como si fuera un marido, pero es el amante (18). Sin más transición ni pausa que un cambio de párrafos, aparece de repente el marido real durmiendo indiferente a su lado: "Y he aquí que estoy extendida al lado de otro hombre dormido" (18), al revés de la imagen anterior: como si fuera un amante, pero es -ipara colmo!- el marido aburrido. Esta yuxtaposición funciona, sin duda, a la manera de la sucesión temporal de las imágenes en el sueño, que conforme la lógica onírica sirve para establecer una conexión causal o una semejanza entre los elementos así representados (Freud, The Interpretation of Dreams, $349,354)$.

Es así que la invención del "perfecto casado" da forma al deseo reprimido de la mujer, ya que ella desplaza en el otro la falta de amor demostrada por el marido (Freud 357). El ensueño de la protagonista encaja perfectamente con uno de los procedimientos de condensación señalados por Freud: la inversión, oposición o intercambio, que "sirve ... para dar expresión a la realización de un deseo" (362); en este caso, mantener vivo el instinto erótico de la protagonista y su anhelo de ser un sujeto deseante, una mujer amada. Conforme una de las leyes fundamentales de la psique - la antítesis o conjunción de contrarios- el amante ausente y fantasmático usurpa el lugar de objeto del deseo en la vida interior de la protagonista, viniendo a ser una especie de doble invertido del esposo o bien su sustituto simbólico. ${ }^{6}$ Paralelamente, entonces, y siguiendo esta misma ley del predominio de las oposiciones, los términos "real" e "imaginario" se invierten en el universo narrativo de Bombal.

Es tal la fuerza de esta inversión psíquica que la escena del amante se suma de un alto grado de intensidad emotiva, puesto que "la intensidad es mayor en esos elementos en cuya formación se ha extendido la mayor dosis de condensación" (Freud, The Interpretation of Dreams, 366). A la par, esta intensidad se comunica en la obra a través del lenguaje poético con que Bombal transfiere la profundidad del inconsciente en material literario. El subtexto del sueño se convierte así en el texto del ensueño, en una transferencia efectuada justamente por las figuras poéticas de la metáfora y la metonimia. Al regresar nuevamente a la escena de ensoñación, notemos el uso del lenguaje figurado para reproducir el efecto de un sueño; es decir, la luminosidad de la imagen onírica con su acompañante carga emotiva. Para empezar, la protagonista, al sumergirse en su ensueño, atraviesa lugares

\footnotetext{
5 "Y pasado mañana será lo mismo, y dentro de un año y dentro de diez; y será lo mismo hasta que la vejez me arrebate todo derecho a amar y a desear, y hasta que mi cuerpo se marchite y mi cara se aje y tenga verguenza de mostrarme sin artificios a la luz del sol" (18).

${ }^{6}$ Freud establece la analogía entre el uso de contrarios en el sueño y los sentidos antitéticos de las palabras en los lenguajes primitivos en Introductory Lectures on Psychoanalysis, SE, XV, 229. Citado en Berg, nota 11, 27.
} 
dotados de esa apariencia fantasmática que produce el dormir: la plaza que emerge lentamente de entre las tinieblas (Bombal 18; Freud 359-360). Ese ámbito evoca el Imaginario lacaniano ya que el amante es la "otra sombra" que se perfila tras la silueta de la protagonista en la plaza oscura (18). No sólo es el amante el "doble" proyectado de la mujer (y la inversión simétrica del marido), sino que todo él se convierte en reflejo de sí mismo, en un espejismo, a tal grado que en su rapsodia amorosa la protagonista declara que "[l]a grave sencillez de su actitud le confiere como una segunda desnudez" (20). Esta cualidad derivada, secundaria, suplementaria del amante indica su función como metáfora del Eros o condensación del deseo reprimido - "Su cuerpo me cubre como una gran ola hirviente ..." (20) - mientras que la escena entera del ensueño ha sido motivada por la lógica del desplazamiento. Índice de esto es la metonimia del deseo, "el perfume del enigmático amigo" que envuelve a la protagonista al consumarse el encuentro sexual (21). $\mathrm{Y}$ es por eso que la escena concluye con un detalle metonímico - la "medallita de oro" que tanto impresiona a la mujer y que el amante guarda "entre el vello castaño del pecho" (21).

Después de la escena nocturna con el amante imaginado, la protagonista se dedica a "soñar" repetidamente la quimera de amor (23), obedeciendo a la cadena metonímica que exige la reproducción del deseo en la memoria (Lacan 203-204), así como a las leyes del lenguaje poético, que opera mediante la repetición y el paralelismo. La protagonista produce otro texto del deseo, que son las cartas dedicadas a su amante en su ausencia, escritas con las mismas palabras que la metonimia del Eros: " "He conocido el perfume de tu hombro y desde ese día soy tuya. Te deseo"' (23). Como en Aura de Carlos Fuentes, donde el tiempo cronológico de la historia cede ante la atemporalidad del deseo, Bombal suspende el tiempo con la eternidad de lo Imaginario, donde la protagonista recrea una y otra vez la memoria del placer ("yo me he hundido en un mundo misterioso donde el tiempo parece detenerse bruscamente" [25]). Conforme la lógica poética, hay una "simetría de estructura" al repetirse la escena de ensoñación, precedida nuevamente por "un baño en el estanque" (Seator 40), cuando aparece el amante misteriosamente entre la niebla adentro de "un carruaje todo cerrado" (25). Más tarde, y anticipando "un segundo encuentro", la protagonista sale a la noche, pero esta vez su marido le comprueba de que su escapada anterior fue solamente un sueño (31-32), lo cual motiva la búsqueda desesperada de la mujer de una prueba de la existencia del amante. Duda que reproduce, a la vez, la incertidumbre del lector (al menos en una primera lectura) acerca de la ocurrencia real $o$ inventada de la escena del abrazo. ${ }^{7}$

Es entonces que la protagonista cobra consciencia de que quizás todo ocurrió durante el sueño (32), y su única defensa contra el embate de lo real es el hallazgo de "[a]lgo material, concreto, indestructible: [el] sombrero de paja" que ha dejado olvidado en casa del hombre-fantasma (24). En uno de los sueños analizados por Freud, el sombrero de paja que aparece en un sueño de mujer adquiere valor simbólico como "fetiche" del falo o metonimia del sexo masculino (The Interpretation of Dreams, 395-397). No es por azar, entonces, que sea Daniel quien destruya de golpe el mundo imaginario de su mujer, puesto

\footnotetext{
${ }^{7}$ Véase Guerra-Cunningham: "la heroína encuentra su razón de ser en una relación amorosa cuya veracidad objetiva no se resuelve en la novela" (51).
} 
que reafirma su papel represivo de representante de la Ley. El patriarcado le prohibe a la mujer el acceso al elusivo y erguido "sombrero de paja," y por lo tanto, le obliga a ella a negar su propio deseo. Como en la noche de bodas, el marido impide el anhelo femenino de comunión erótica, manteniéndose él mismo enclausurado en su soledad.

Antes, a través del ensueño, la protagonista había logrado posponer, durante un tiempo, la muerte-en-vida de su matrimonio por la rememoración de "un deseo muerto," muerto ya que acontece puramente a nivel imaginario (Lacan 203). Ahora, una vez desengañada, y con su universo afectivo en ruinas, no tiene defensa psíquica contra la muerte de su deseo. El último destino de la protagonista es resignarse a una vida sin deseo en cumplimiento de sus "deberes" de esposa, que la transforma figurativamente en una "muerta": “¿Mi vida no es acaso ya el comienzo de la muerte?" (42-43). Esta impresión de muerte se condensa al principio del relato, con la imagen de una joven que yace en el ataúd (11), que algunos críticos han identificado erróneamente con la primera esposa de Daniel (Sosnowski 369). ${ }^{8}$ En el sistema poético de Bombal, "la muchacha que yace en ese ataúd blanco" (11) funciona a la manera de una imagen onírica invertida, de esas que aparecen al inicio de un sueño pero que, en realidad, anticipan el final al explicar la causa o motivo del sueño subsiguiente (Freud, The Interpretation of Dreams, 363). De acuerdo a esta misma lógica, la muerta que aparece al principio del relato prefigura el destino trágico que cumple la protagonista al final; la aniquilación de su deseo y el apagar de toda esperanza de realizarse como mujer. De igual manera, Ana María, La amortajada, desea morir al ver frustrados sus instintos vitales y su capacidad pasional, encontrando su único goce al descender lentamente a la tierra y fundirse con la materia prima de la naturaleza.

La conjunción e intercambio entre vida/muerte, Eros y Thanatos que caracteriza a la vida instintiva se cifra en la imagen de la niebla, que está asociada, como sugiere la autora, con la muerte del deseo y el correspondiente deseo de muerte. Pero, ¿qué es la niebla sino el producto mismo de la condensación? Tanto a nivel literal, de las gotas en la nube, como en el sentido figurado de la condensación que produce el sueño. Asimismo, La última niebla que "presta a las cosas un carácter de inmovilidad definitiva" (43), alude autorreferencialmente al texto de la ficción, al "ensueño" literario que ha dejado en la fijeza de las letras el trazo del deseo femenino.

\section{Obras citadas}

Agosín, Marjorie. "Entrevista con María Luisa Bombal”, The American Hispanist, 3/21 (noviembre 1977) 5-6.

Las desterradas del paraiso, protagonistas en la narrativa de María Luisa Bombal. Nueva York: Senda Nueva de Ediciones, 1983.

Alonso, Amado. "Aparición de una novelista". Prólogo a La última niebla, $3^{\mathrm{a}}$ edición. Santiago de Chile: Nascimento, 1962.

\footnotetext{
${ }^{8}$ Bombal aclara que "[1]a joven muerta no tiene nada que ver con la esposa de Daniel, [sic] es importante porque, por primera vez, mi protagonista ve una persona muerta, conoce la muerte ... y así, la niebla también la ataca por primera vez". Entrevista concedida a Guerra-Cunningham y citada en su libro, nota $18,54$.
} 
Berg, Temma F. "Suppressing the Language of (Wo)man: The Dream as a Common Language". Temma F. Berg, Anna Shannon Elfenbein, Jeanne Larsen and Elisa Kay Sparks, eds. Engendering the Word-Feminist Essays in Psychosexual Poetics. Urbana and Chicago: University of Illinois Press, 1989. 3-28.

Bombal, María Luisa. La última niebla. La amortajada. Re-edición. Barcelona: Seix Barral, 1984.

Freud, Sigmund. The Interpretation of Dreams. Traducción James Strachey. Nueva York: Avon Books, 1965.

Beyond the Pleasure Principle. Traducción James Strachey. Nueva York: Liveright, 1970.

Goiç, Cedomil. "La última niebla". La novela chilena: los mitos degradados. Santiago de Chile: Editorial Universitaria, 1968. 144-162.

Guerra-Cunningham, Lucía. La narrativa de María Luisa Bombal: una visión de la existencia femenina. Madrid: Editorial Playor, 1980.

Lacan, Jacques. "De nuestros antecedentes". "La instancia de la letra en el inconsciente o la razón desde Freud", Escritos I. Traducción Tomás Segovia. México: Siglo XXI, 1971. 3-10, 179-213.

Seator, Lynette. "La creación del ensueño en La última niebla", Armas y letras 8/4 (Monterrey, México, 1965) 38-45.

Sosnowski, Saúl. "El agua, motivo primordial de La última niebla", Cuadernos hispanoamericanos, 277-278 (julio-agosto 1973) 365-374.

Vidal, Hernán. María Luisa Bombal: la feminidad enajenada. Barcelona: Hijos de José Bosch, S.A., 1976. 
